\title{
Auditory Temporal Resolution in Individuals with Diabetes Mellitus Type 2
}

\author{
Rajkishor Mishra ${ }^{1}$ Himanshu Kumar Sanju ${ }^{2}$ Prawin Kumar ${ }^{2}$ \\ ${ }^{1}$ Department of Audiology, Bloom Senso Hearing Center, Kolkata, \\ West Bengal, India \\ 2 Department of Audiology, AllSH, Manasagangothri, Mysore,

\begin{abstract}
Address for correspondence Himanshu Kumar Sanju, MD, Audiology, Department of Audiology, AlISH, Manasagangothri, Mysore, Karnataka, India 570006 (e-mail: himanshusanjuaiish@gmail.com).
\end{abstract} Karnataka, India

Int Arch Otorhinolaryngol 2016;20:327-330.

\begin{abstract}
Keywords

- temporal auditory area

- diabetes complications

- auditory stimulation

Introduction "Diabetes mellitus is a group of metabolic disorders characterized by elevated blood sugar and abnormalities in insulin secretion and action" (American Diabetes Association). Previous literature has reported connection between diabetes mellitus and hearing impairment. There is a dearth of literature on auditory temporal resolution ability in individuals with diabetes mellitus type 2 .

Objective The main objective of the present study was to assess auditory temporal resolution ability through GDT (Gap Detection Threshold) in individuals with diabetes mellitus type 2 with high frequency hearing loss.

Methods Fifteen subjects with diabetes mellitus type 2 with high frequency hearing loss in the age range of 30 to 40 years participated in the study as the experimental group. Fifteen age-matched non-diabetic individuals with normal hearing served as the control group. We administered the Gap Detection Threshold (GDT) test to all participants to assess their temporal resolution ability.

Result We used the independent $t$-test to compare between groups. Results showed that the diabetic group (experimental) performed significantly poorer compared with the non-diabetic group (control).

Conclusion It is possible to conclude that widening of auditory filters and changes in the central auditory nervous system contributed to poorer performance for temporal resolution task (Gap Detection Threshold) in individuals with diabetes mellitus type 2 . Findings of the present study revealed the deteriorating effect of diabetes mellitus type 2 at the central auditory processing level.
\end{abstract}

\section{Introduction}

Diabetes mellitus is a multisystem disorder. It is a disorder of carbohydrate metabolism which occurs because of absolute or relative insulin deficiency. Along with metabolic disturbance, various pathologic changes in the human body have been seen. Previous literature reported that the hearing impairment seen in diabetes mellitus is a progressive bilateral sensorineural hearing loss of gradual onset, which mainly affect higher frequencies, similar to age-related hearing loss. ${ }^{1}$ We also found that hearing loss may be unilateral, sudden, with and without vestibular disorder. Evidence showed that endolymphatic sac vasculature plays an important role in the pathogenesis of sensorineural hearing loss. ${ }^{2,3}$ The main cause of hearing loss in diabetic patients is vascular insufficiency to the cochlea. Uncontrolled diabetes may cause vasculopathy in stria vascularis of the cochlea. Researchers have reported diffused thickening of basilar membrane observed in vascular endothelium, which is called received

October 14, 2015

accepted

October 28, 2015

published online

February 1, 2016
DOI http://dx.doi.org/

10.1055/s-0035-1571207. ISSN $1809-9777$.
Copyright $(2016$ by Thieme Publicações License terms Ltda, Rio de Janeiro, Brazil 
diabetic microangiopathy. ${ }^{4,5}$ Several studies also reported that microangiopathy is responsible for hearing loss in diabetic individuals $^{6,7}$ and on the participation of smaller vessels in the inner ear that leads to hypoxia and cause hearing loss. ${ }^{4,8}$ Maia et al reported that diabetic neuropathy and microangiopathy can cause high frequency hearing loss. ${ }^{9}$

Moreover, hearing loss was present at all frequencies from $250 \mathrm{~Hz}$ to $8000 \mathrm{~Hz}$ in diabetic individuals. ${ }^{8}$ Studies on hearing thresholds on subjects with diabetes revealed mild to moderate high-frequency sensorineural hearing loss, ${ }^{10}$ whereas other studies showed higher thresholds in individuals with diabetes mellitus at all frequencies tested. Previous literature also reported no difference in speech discrimination scores among diabetic patients and the normal population. ${ }^{11} \mathrm{~A}$ study by Bajaj et al reported poor speech perception in noise among diabetic patients. ${ }^{12}$ Researchers also reported poor perception of speech in noise in individuals with high frequency hearing loss. ${ }^{13,14}$ Poor perception of speech in noise in individuals with high frequency hearing loss may be due to poor auditory processing of the signal at a given frequency region due to loss of audibility. ${ }^{15}$ Cochlear lesion can also affect intensity and frequency coding, as investigated by various researchers. ${ }^{16,17}$ Previous studies have mostly been conducted with hearing loss evaluation and speech perception ability in diabetic populations.

There is a dearth of literature regarding auditory temporal resolution skill in individuals with diabetes mellitus with high frequency hearing loss. Temporal resolution refers to the ability of the auditory system to identify rapid changes in the envelop of a sound stimulus over time. ${ }^{18}$ The Gap Detection Threshold (GDT) test is a valuable, cost effective tool to assess the ability of an individual to detect minimal small gap between two stimuli of equal characteristics. The GDT can be defined as the shortest duration of gap within a sound that individual can detect. This test is useful and cost effective in assessing auditory temporal resolution skill. ${ }^{19}$ GDT have been used by previous researchers to study cortical lesion. ${ }^{20}$ Musiek et al reported GDT is a valuable tool in assessing temporal resolution deficit in brainstem, as well as cortical lesions. ${ }^{21}$ Therefore, the present study aimed to compare auditory temporal resolution skill in individuals with diabetes mellitus with high frequency hearing loss with agematched normal hearing subjects by assessing Gap Detection Threshold (GDT) between the two groups (experimental and control).

\section{Methods}

\section{Participants}

For this study, we recruited thirty participants that provided their informed written consent. We divided them in two groups (Experimental and Control). The experimental group consisted of 15 individuals ( 8 men and 7 women) with diabetic mellitus type 2 in the age range of 30 to 40 years (mean age of 37.3 years). The control group, in turn, consisted of 15 age-matched non-diabetic individuals ( 8 men and 7 women) in the age range of 30 to 40 years (mean age of 38.1 years). The rationale behind selecting this age range was to avoid the effect of age related hearing loss.

\section{Participants Selection Criteria}

All the participants in Group 1 (Experimental) had reduced hearing sensitivity (from mild to severe degree) in both ears as defined by pure tone thresholds greater than $15 \mathrm{dBHL}$ at 2000, 4000, and $8000 \mathrm{~Hz}$, with normal hearing sensitivity at 250, 500 and $1000 \mathrm{~Hz}$. Slope was steep when higher than $25 \mathrm{~dB} /$ octave. All subjects had normal middle ear functioning as revealed by an A-type tympanogram and presence of acoustic reflexes at all frequencies except $2000 \mathrm{~Hz}$ and $4000 \mathrm{~Hz}$ for both ipsi and contralateral stimulation. There was no history or presence of any other otological, neuromuscular, or neurological problem among both groups. Neither was there any history of noise exposure.

As for Group 2 (Control), all the participants had normal air conduction and bone conduction thresholds ( $\leq 15 \mathrm{~dB} \mathrm{HL})$ at all octave frequencies from $250 \mathrm{~Hz}$ to $8000 \mathrm{~Hz}$. They all presented normal middle ear functioning with A-type tympanogram at $226 \mathrm{~Hz}$ probe tone having normal acoustic reflexes (Ipsilateral and Contralateral) in both ears.

\section{Test Environment}

We conducted all the tests in a sound treated.

\section{Instrumentation}

We used a calibrated dual channel Madsen MA-53 clinical audiometer (Gn Otometrics A/S, Taastrup, Denmark) for pure tone audiometry. We sued a calibrated GSI-Tympstar Immittance meter (GSI, Eden Prairie, U.S.A.) for tympanometry and reflexometry. We used a personal computer loaded with Matlab R 2011a software (Mathworks, Natick, U.S.A.) for GDT (Gap Detection Threshold).

\section{Procedure}

Pure tone thresholds were obtained using modified versions of the Hughson and Westlake procedure (Carhart \& Jerger, 1959) across octave frequencies from $250 \mathrm{~Hz}$ to $8000 \mathrm{~Hz}$ for air conduction and from 500 to $4000 \mathrm{~Hz}$ for bone conduction. ${ }^{22}$ We used the middle ear analyzer (GSI-Tympstar, Eden Prairie, U.S.A.) to carry out tympanometry using a probe tone frequency of $226 \mathrm{~Hz}$ and to obtain ipsilateral and contralateral acoustic reflexes thresholds at $500 \mathrm{~Hz}$, $1000 \mathrm{~Hz}, 2000 \mathrm{~Hz}$, and $4000 \mathrm{~Hz}$. Gap detection threshold was assessed using 750 milliseconds gaussian noise including a gap in its temporal center. Gap duration varied according to listener performance using maximum likelihood procedure. The noise had 0.5 milliseconds cosine ramps at the beginning and end of the gap. In the three alternative forced choice task, the reference stimulus was always a 750 milliseconds white noise without gap, whereas the variable stimulus contained a gap. We took the minimum gap duration required to perceive a gap in noise as threshold.

\section{Statistical Analysis}

We conducted descriptive statistics to find mean and standard deviation of GDT of the groups. We used an independent t-test to compare between the experimental and the control group for GDT. 
Table 1 Mean and SD of gap detection threshold (GDT) for Group 1 (experimental) and Group 2 (control)

\begin{tabular}{|l|l|l|l|l|}
\hline Measures & \multicolumn{3}{|l|}{ Groups } \\
\cline { 2 - 5 } & \multicolumn{3}{|l|}{$\begin{array}{l}\text { Group 1 } \\
\text { (Experimental) }\end{array}$} & \multicolumn{2}{l|}{$\begin{array}{l}\text { Group 2 } \\
\text { (Control) }\end{array}$} \\
\cline { 2 - 5 } & Mean & SD & Mean & SD \\
\hline GDT (ms) & 6.49 & 0.81 & 3.33 & 0.79 \\
\hline
\end{tabular}

Abbreviation: GDT, gap detection threshold; SD, standard deviation.

\section{Results}

In the present study all participants underwent Gap Detection Threshold test. We analyzed the data using SPSS software Version 18 (IBM Corporation, Armonk, U.S.A.).

\section{Gap Detection Threshold (GDT) Test}

We conducted the GDT test for both groups. - Table 1 shows mean and standard deviation (SD) of gap detection threshold. Descriptive statistical analyses showed that GDT was better for Group 2 when compared with Group 1. - Fig. 1 shows a graphical presentation of the outcome.

We administered the independent $t$-test to compare GDT between two groups. It showed a statistically significant difference between the groups $(\mathrm{t}=-7.82 ; \mathrm{df}=28 ; p<0.05)$.

\section{Discussion}

The results of the present study showed poor auditory temporal resolution skill in patients with diabetes mellitus type 2 having high frequency hearing loss compared with age matched non-diabetic normal hearing subjects. The present study revealed a statistically significant difference in GDT between patients with diabetes mellitus type 2 having high frequency hearing loss (Group 1) and age-matched nondiabetic normal hearing subjects (Group 2). Absence of the specific literature on GDT in diabetic individuals renders it difficult to explain the result found in the present study. However, widened auditory filter at higher frequencies and poor central auditory processing due to diabetes mellitus type 2 could be a possible explanation for poorer gap detection task.

The present study showed poor performance in temporal resolution task by diabetic patients which revealed changes in the central auditory system. Previous studies on diabetic humans and rats showed hearing impairment mainly caused by edema in stria vasularis and reduction in number of spiral ganglion cells and outer hair cells. ${ }^{23-25}$ Hearing loss in HF region suggests that the cochlea may have been damaged by angiopathy in the stria vascularis, spiral ligament, and edema in the stria vascularis, which leads to poor frequency and intensity coding. ${ }^{16,26,27}$ Previous literature reports poor auditory brainstem response with prolonged latencies of wave III, V and inter-peak I-III in diabetic population. Prolonged latencies were also noted for wave $\mathrm{V}$ and interpeak III-V, inter-peak I-III, and I-V in diabetic individuals at 90 dBnHL. ${ }^{28}$ This possibly suggests the involvement of the relay stations of different order neurons in the central auditory nervous system. The present study supports the study done by McCrimmon et al, which also reported poor temporal and auditory processing in individuals with diabetes mellitus. ${ }^{29} \mathrm{~A}$ similar study done by Sommerfield revealed that tests of immediate verbal and immediate visual memory were significantly poor during hypoglycemia. ${ }^{30}$ The adverse effect of hypoglycemia on working memory and delayed memory was more profound. The present studýs findings showed poor temporal resolution skill can be due to widening of auditory filter and changes in the central auditory nervous system contributing to the poorer performance on the temporal resolution task in diabetic individuals.

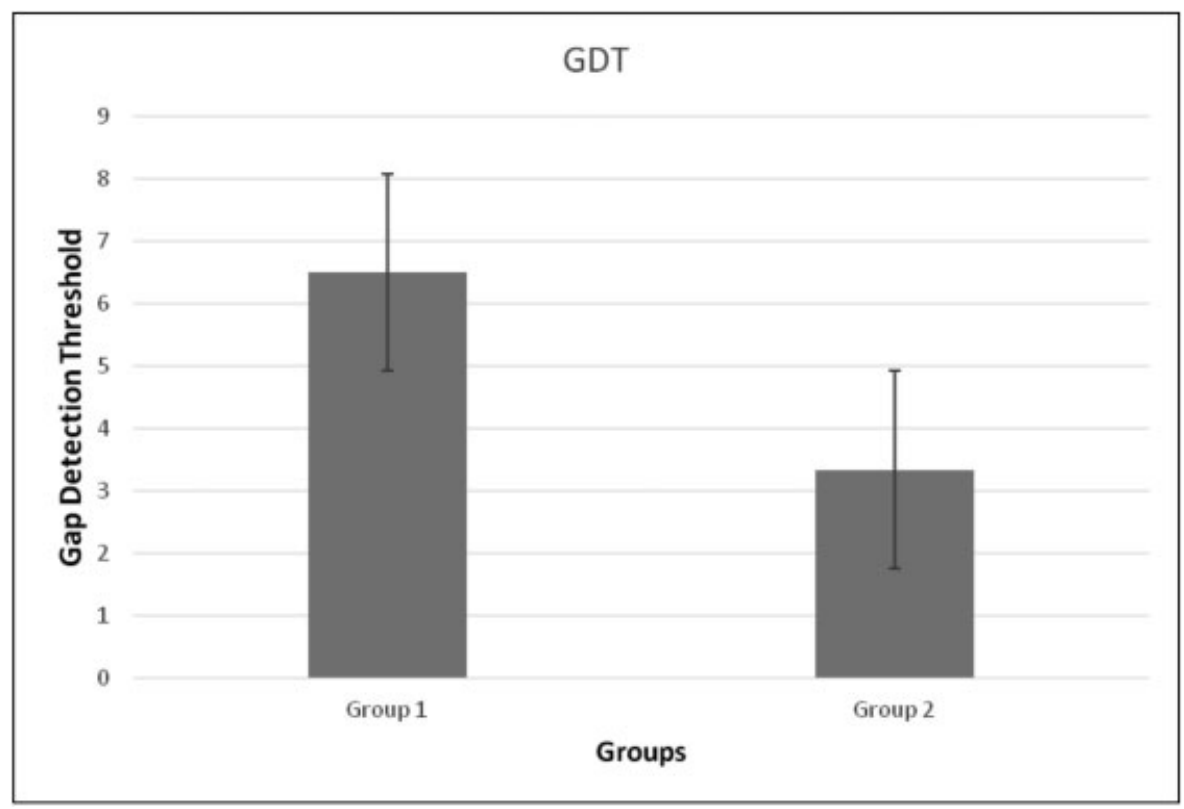

Fig. 1 Mean values of Gap Detection Threshold (GDT) for Group 1 (Experimental) and Group 2 (Control). 


\section{Conclusion}

Present study findings showed poor temporal resolution skills in individuals with diabetes mellitus type 2 compared with control group. Poor auditory temporal resolution may cause poor speech perception in these individuals in quiet, as well as in noise. Findings revealed the deteriorating effect of diabetes mellitus type 2 at the central auditory processing level. Thus, we would suggest screening all patients with diabetes for temporal resolution ability to understand the mechanism underlying speech perception in noise.

\section{References}

1 Jorgensen MB, Buch NH. Studies on the sense of smell and taste in diabetics. Acta Otolaryngol 1961;53(2):539-545

2 Leone CA, Feghali JG, Linthicum FH Jr. Endolymphatic sac: possible role in autoimmune sensorineural hearing loss. Ann Otol Rhinol Laryngol 1984;93(3 Pt 1):208-209

3 Gussen R. Vascular mechanisms in Meniere's disease. Theoretical considerations. Arch Otolaryngol 1982;108(9):544-549

4 Malpas S, Blake P, Bishop R, Robinson B, Johnson R. Does autonomic neuropathy in diabetes cause hearing deficits? N Z Med J 1989;102(874):434-435

5 Konrad-Martin D, Austin DF, Griest S, McMillan GP, McDermott D, Fausti S. Diabetes-related changes in auditory brainstem responses. Laryngoscope 2010;120(1):150-158

6 Makishima K, Tanaka K. Pathological changes of the inner ear and central auditory pathway in diabetics. Ann Otol Rhinol Laryngol $1971 ; 80(2): 218-228$

7 Costa OA. Inner ear pathology in experimental diabetes. Laryngoscope 1967;77(1):68-75

8 Wackym PA, Linthicum FH Jr. Diabetes mellitus and hearing loss: clinical and histopathologic relationships. Am J Otol 1986;7(3): 176-182

9 Maia CA, Campos CA. Diabetes mellitus as etiological factor of hearing loss. Braz J Otorhinolaryngol 2005;71(2):208-214

10 Celik O, Yalçin S, Celebi H, Oztürk A. Hearing loss in insulindependent diabetes mellitus. Auris Nasus Larynx 1996;23(8): 127-132

11 Cullen JR, Cinnamond MJ. Hearing loss in diabetics. J Laryngol Otol 1993;107(3):179-182

12 Bajaj G, Puthuchery S, Bhat J, Ranjan R. Effect of type 2 diabetes on speech perception in noise. Int J Innov Res Dev 2014;3(4): 50-54

13 Dubno JR, Dirks DD, Morgan DE. Effects of age and mild hearing loss on speech recognition in noise. J Acoust Soc Am 1984;76(1):87-96
14 Stuart A, Phillips DP. Word recognition in continuous and interrupted broadband noise by young normal-hearing, older normalhearing, and presbyacusic listeners. Ear Hear 1996;17(6):478-489

15 Moore BC. Perceptual consequences of cochlear hearing loss and their implications for the design of hearing aids. Ear Hear 1996; 17(2):133-161

16 Florentine M, Reed CM, Rabinowitz WM, Braida LD, Durlach NI, Buus S. Intensity perception. XIV. Intensity discrimination in listeners with sensorineural hearing loss. J Acoust Soc Am 1993; 94(5):2575-2586

17 Simon HJ, Yund EW. Frequency discrimination in listeners with sensorineural hearing loss. Ear Hear 1993;14(3):190-201

18 Plack CJ, Viemeister NF. Suppression and the dynamic range of hearing. J Acoust Soc Am 1993;93(2):976-982

19 Lister J, Besing J, Koehnke J. Effects of age and frequency disparity on gap discrimination. J Acoust Soc Am 2002;111(6):2793-2800

20 Efron R, Yund EW, Nichols D, Crandall PH. An ear asymmetry for gap detection following anterior temporal lobectomy. Neuropsychologia 1985;23(1):43-50

21 Musiek FE, Shinn JB, Jirsa R, Bamiou DE, Baran JA, Zaida E. GIN (Gaps-In-Noise) test performance in subjects with confirmed central auditory nervous system involvement. Ear Hear 2005; 26(6):608-618

22 Carhart R, Jerger J. Preferred method for clinical determination of pure-tone thresholds. J Speech Hear Disord 1959;24(4):330-335

23 Raynor EM, Carrasco VN, Prazma J, Pillsbury HC. An assessment of cochlear hair-cell loss in insulin-dependent diabetes mellitus diabetic and noise-exposed rats. Arch Otolaryngol Head Neck Surg 1995;121(4):452-456

24 Fukushima H, Cureoglu S, Schachern PA, et al. Cochlear changes in patients with type 1 diabetes mellitus. Otolaryngol Head Neck Surg 2005;133(1):100-106

25 Lee HS, Kim KR, Chung WH, Cho YS, Hong SH. Early sensorineural hearing loss in ob/ob mouse, an animal model of type 2 diabetes. Clin Exp Otorhinolaryngol 2008;1(4):211-216

26 Nelson DA, Freyman RL. Psychometric functions for frequency discrimination from listeners with sensorineural hearing loss. J Acoust Soc Am 1986;79(3):799-805

27 Schroder AC, Viemeister NF, Nelson DA. Intensity discrimination in normal-hearing and hearing-impaired listeners. J Acoust Soc Am 1994;96(5 Pt 1):2683-2693

28 Gupta R, Aslam M, Hasan S, Siddiqi S. Type -2 diabetes mellitus and auditory brainstem responses-a hospital based study. Indian J Endocrinol Metab 2010;14(1):9-11

29 McCrimmon RJ, Deary IJ, Frier BM. Auditory information processing during acute insulin-induced hypoglycaemia in non-diabetic human subjects. Neuropsychologia 1997;35(12):1547-1553

30 Sommerfield AJ, Ewing FM, Strachan MW, Deary IJ, Aitken G, Frier BM. Self-treatment of mild symptomatic hypoglycaemia by people with insulin-treated diabetes. Diabet Med 2003;20(8):686-687 